\title{
СТАБИЛЬНОСТЬ КАК ФИЛОСОФСКАЯ КАТЕГОРИЯ, АКТУАЛИЗИРОВАННАЯ ПРИМЕНИТЕЛЬНО К СОЦИАЛЬНЫМ НАУКАМ ${ }^{1}$
}

\section{STABILITY AS A PHILOSOPHICAL CATEGORY, UPDATED IN RELATION TO THE SOCIAL SCIENCES ${ }^{2}$}

\section{Usenkov}

Summary: The subject of the study is stability as a philosophical category that is relevant to the social sciences, primarily to law. It is concluded that most social systems have an open and dissipative character, and in their optimal state they are characterized by dynamic stability. The author identifies the signs of a dynamically stable social system: selfidentity, relative constancy of elements, reasonable intensity of changes, adaptability. Thus, the dynamic stability of a social system means the preservation of its stability, that is, an adaptive and reasonable intensity of changes while maintaining self-identity and the relative constancy of the elements, in a certain time perspective.

Keywords: stability, dynamism, dialectics, properties of systems, social systems.
Л юбое исследование динамических свойств права вынужденно оперирует понятием «стабильность», осмысление которого лежит в плоскости философии. Актуализация философской категории применительно к правовой реальности, то есть выведение из нее более конкретного и относимого к отдельной социокультурной области - праву - понятия, имеет свои пределы. Стабильность сама по себе не теряет своего всеобщного характера, не становится понятием юридической науки. Актуализация, таким образом, позволяет, с одной стороны, выделить стабильность права как особую категорию и конкретизировать ее самостоятельные свойства, а с другой - сохранить преемственность понятия, его философское начало и синергетическую связь с другими областями познания, поскольку, являясь культурным феноменом, право взаимозависимо с иными продуктами взаимодействия человеческого и природного миров.

Покой и движение материи являются основаниями понятий «стабильность» и «нестабильность». Явно или имплицитно присутствуя в ключевых философских концепциях, они по сегодняшний день остаются объектом

\author{
Усенков Иван Алексеевич \\ Аспирант, Волгоградский государственный университет \\ i.usenkov@volsu.ru
}

Аннотация: Предметом исследования является стабильность как философская категория, актуализированная к социальным наукам, в первую очередь, к праву. Сделан вывод о том, что большинство социальных систем имеют открытый и диссипативный характер, в оптимальном состоянии им свойственна динамическая стабильность. Автором выявлены признаки динамически стабильной социальной системы: самоидентичность, относительное постоянство элементов, разумная интенсивность изменений, адаптивность. Таким образом, динамическая стабильность социальной системы означает сохранение ей устойчивости, то есть адаптивной и разумной интенсивности изменений при сохранении самоидентичности и относительного постоянства элементов, в определенной временной перспективе.

Ключевые слова: стабильность, динамизм, диалектика, свойства систем, социальные системы.

пристального внимания ученых. Стабильность в последнее время получает новое прочтение не только в социогуманитарных науках. Одним из ключевых изменений XX века в естественнонаучной картине мира стал отказ от детерминизма, обусловивший новое понимание соотношения и значения стабильности и нестабильности.

Во многом благодаря популярности диалектики в развития философской мысли, стабильность, явно или латентно, осмыслялась ключевыми мыслителями различных эпох. Философия науки, в том числе социальногуманитарной, и философия искусства также на протяжении всего своего развития так или иначе затрагивают стабильность. Социальная философия занимается проблемами актуализированной категории стабильности, в том числе стабильности социальных систем.

При этом развитие мира через противоречия по сей день исследуется преимущественно в гегелевских категориях, однако менее оптимистично и более осторожно. Возрождение понятия «энтелехия» Гуссерлем во многом связано со скепсисом в отношении того, что развитие 
человечества обусловлено ее включенностью в этот процесс. Энтропия и регресс становятся лейтмотивом исследований пессимистично настроенных философов и обязательной оговоркой для остальных, обосновывающих развитие, но развитие в виде спирали, обязательно содержащей периоды упадка. Стабильность реальности как воплощения абсолютного духа не только не достигнута, но и более не постулируется в качестве достижимой цели. Таким образом, если в нынешнюю эпоху постмодерна и можно говорить о стабильности как философской категории, то она будет не стабильностью неподвижности, развития, движения к реализации абсолютного духа или энтелехии человеческой природы, а стабильностью неизбежности неравновесных прогресса и упадка в результате субъективного синтеза как решения возникающих противоречий.

Исследование философской категории «стабильность» является крайне важным для сущностного понимания основ стабильности права, однако само по себе не несет какого-либо практического эффекта для ее исследования. С другой стороны, работа над исключительно прикладной составляющей правовой стабильности элиминирует философскую глубину самого понятия стабильности. Это обуславливает необходимость воспользоваться методом актуализации философский категорий, избрав частный для философии, но общий для права институт, выводы о стабильности которого вместе с категориальным аппаратом будут применимы к правовой стабильности.

Таким институтом могут являться социальные системы - предмет изучения социальной философии [3, С. 189]. Характерна классификация стабильности социальных систем, предлагаемая данной наукой:

1. Статическая стабильность:

a. неподвижная (статичная система);

b. подвижная (равновесная, т.е. сбалансированная система).

2. Динамическая стабильность [1, С. 3].

Как видно из названий, даже среди подвидов статической стабильности абсолютная неизменяемость характеризует только один. В целом же статическая стабильность связывается с эффективным сопротивлением социальной системы внешним воздействиям, низкой степенью восприимчивости к ним.

Абсолютно неподвижная социальная система, замкнутая в себе и изолированная от внешнего мира, не способна существовать на протяжении сколь бы то ни было значительного промежутка времени в связи с неизбежностью трансформации или распада под давлением внутренних или внешних факторов.

Равновесные системы представляют собой попытку избежать врожденной нежизнеспособности статичных систем с помощью признания принципиальной возможности незначительных изменений и некоторой открытости к среде. При этом изменения в сбалансированных системах представляют собой, по сути, не более чем флуктуации исходных состояний, не снимающих внутренних и внешних противоречий, а допускаемая, пусть и небольшая, степень открытости рано или поздно приводит к потере равновесности и краху подобных систем. Попытки реформирования путем произвольного перевода социальной системы из одного стабильного состояния в другое не влияют положительным образом на жизнеспособность таких систем, поскольку обычно изменения не релевантным реальным запросам перемен. Например, большинство тоталитарных режимов представляют собой как раз попытку построить систему общества, подвергающуюся изменениям исключительно по воле властной элиты и не более, чем, например, того требует научно-технический процесс.

Поскольку же большинство социальных систем имеют открытый и диссипативный характер, в оптимальном состоянии им свойственна динамическая стабильность, то есть способность к трансформации сообразно адаптированному воздействию окружающей среды и внутренним потребностям системы с сохранением определенной степени ее устойчивости [2, С. 167]. Из данного определения следуют такие признаки динамически стабильной системы, как:

1. Самоидентичность. О сохранении стабильности на протяжении определенного промежутка времени можно говорить лишь в том случае, если речь идет об одном объекте, пусть и изменившимся. Данный тезис содержит в себе два проблемных аспекта. Каким должен быть контрольный промежуток времени? Какие элементы системы должны остаться неизменными?

Полагаем, что ответ на первый вопрос не имеет принципиального значения. Отлеживать стабильность системы можно как на протяжении краткосрочных, так и длительных периодов времени. При этом следует понимать, что стабильность в них будет преимущественно отличаться. Так, динамическая стабильность в краткосрочном промежутке времени предполагает сохранение структуры системы, качественных и количественных показателей элементов и признаков (за исключением незначительных изменений структуры, преимущественно связанных с ее усложнением), при этом сами такие компоненты и свойства могут меняться. Таким образом, сохранение структуры, качества и количества составляющих систему элементов является признаком ее самоидентичности. Однако в долгосрочном периоде динамическая стабильность социальной системы может включать значительные изменения ее структуры. По- 
казателями самоидентичности при этом являются: постепенный и преемственный характер таких изменений, единство и непрерывность осознания системы ее эксплуатантами или самосознания ее акторов, полное или преимущественное сохранение принципов функционирования системы.

2. Относительное постоянство элементов. Несмотря на первичную роль структуры в сохранении стабильности системы, устойчивая структура в условиях постоянной смены даже качественно однородных элементов не всегда означает стабильную систему. Количество и частота подобных изменений должны быть ограничены. При этом обобществленный характер выводов настоящего исследования как сделанных в отношении любых социальных систем не позволяет привязать этот и все иные критерии к конкретным числовым показателям, но даже в отношении конкретных социальных систем возможность формулирования определенных математических значений имеет дискуссионных характер.

3. Разумная интенсивность изменений. Соотносимость эволюции системы с изменениями в фундаментальных отношениях, на которых она вы- строена, означает одновременно динамизм как неизбежную связь с окружающей реальностью, и ограниченность этого динамизма, в отсутствие которой система разрушается из-за потери самоидентичности или смерти под влиянием внешних воздействий из-за разрыва связей с иными элементами макросистемы.

4. Адаптивность. Способность под воздействием внешних и внутренних факторов сохранять свои свойства и при этом в необходимой степени мимикрировать является условием выживания любой социальной системы.

Таким образом, стабильность социальных систем в современных исследованиях контекстуально подразумевает именно динамическую стабильность как оптимальное и желаемое, а зачастую - и единственно возможное на протяжении сколько-нибудь продолжительного промежутка времени состояние. Динамическая стабильность социальной системы означает сохранение ей устойчивости, то есть адаптивной и разумной интенсивности изменений при сохранении самоидентичности и относительного постоянства элементов, В определенной временной перспективе.

\section{ЛИТЕРАТУРА}

1. Абдуллаева Р.А. Стабильность как одно из возможных состояний социальной системы / Р.А. Абдуллаева // Социально-экономические и технические системы: исследование, проектирование, оптимизация. - 2006. - № 12. - С. 1-7.

2. Глобальная этносоциология / А.К. Гуц; М-во общ. и проф. образования Рос. Федерации. Ом. гос. ун-т. - Омск : ОмГУ, 1997. - 212 с.

3. Зайцева Л.Ю. Стабильность и нестабильность как философские категории и содержание развития социума / Л.Ю. Зайцева // Булгаковские чтения. 2011. - № 5. - С. 189-194.

(с) Усенков Иван Алексеевич (i.usenkov@volsu.ru).

Журнал «Современная наука: актуальные проблемы теории и практики» 